\title{
Changes in the composition and properties of biochar after one-year application
}

\author{
Marya Bovsun $^{1}$, Olga Nesterova $^{1}$, Viktoriia Semal $^{1,2 *}$, Alexandra Khokhlova $^{1}$, and Nikolay \\ Sakara $^{3}$ \\ ${ }^{1}$ Far Eastern Federal University, 8 Sukhanova St., Vladivostok 690090, Russia \\ ${ }^{2}$ Federal Scientific Center of the East Asia Terrestrial Biodiversity, Far Eastern Branch of the Russian \\ Academy of Sciences, 159 Prospekt Stoletiya, Vladivostoka Ave., Vladivostok 690022, Russia \\ ${ }^{3}$ Seaside Vegetable Experimental Station of the All-Russian Scientific Research Institute of \\ Vegetables, 57/1 Kubanskaya St., Artyom 692779, Russia
}

\begin{abstract}
The study examines the change in the properties of biochar obtained from Betula alba tree residues after its application in a field growing experiment for two growing periods in the areas with different water-air conditions (both with and without drainage). The results obtained after the first growing period showed a noticeable change in the indicators. The $\mathrm{pH}$ values in the biochar sample after the first growing period decreased sharply by 1.3 and 0.7 units in the areas with and without drainage, respectively, compared to the initial $\mathrm{pH}$ value of 8.09. After the second growing period, the change in $\mathrm{pH}$ value was not significant. The values of ash elements increased sharply, the content of volatile compounds decreased slightly. Water retention capacity improved. After the first growing period, water retention capacity almost doubled and it changed slightly in the sample with the biochar after its application in the second growing period.
\end{abstract}

\section{Introduction}

Biochar is a high-carbon and highly porous product obtained by biomass pyrolysis. Due to its highly porous carbon structure, biochar is able to improve water retention capacity and increase soil surface area [1]. It has a number of physical and chemical properties affecting $\mathrm{pH}$, soil aggregation, nutrient availability, organic carbon availability [2-5], and it promotes plant growth, increases crop yields, and reduces the amount of contaminants [6]. Nevertheless, there are many types of biochar that have a wide range of physical and chemical indicators that affect soil properties to varying degrees.

The soil also has a large effect on biochar. In soils, biochar, due to its strong resemblance with organic matter and inorganic ions, undergoes a number of biochemical reactions and physical processes that lead to changes in its properties over time [4]. The change in the properties of biochar can go towards both improvement and deterioration. This uncertainty of results is explained by differences in experimental conditions associated with either a wide range of soil and climate indicators during a field experiment or with

* Corresponding author: semal.va@dvfu.ru 
artificially created characteristics in laboratory research. This raises a number of issues related to the causes of the changes, their degree, rate and duration when the biochar comes in contact with soil or the environment [8].

The paper examines the changes in the properties of the biochar applied in a growing field experiment during two periods of vegetation. In order to achieve the aims of the study, the biochar properties were evaluated before the experiment, after the first and second growing periods. Then the degree of change in the properties of the biochar were also evaluated based on the results.

\section{Methods}

\subsection{Field experiment}

The influence of biochar on soil properties and yield was studied in the framework of a stationary field experiment established in 2018 - 2019 on the territory of Primorskaya vegetable experimental station VNIIO LLC (Surazhevka village, Primorsky region, Russia) (Fig.1). On the territory of the station were selected two fields that were comparable in terms of terrain and soil conditions, one of which had a drainage system, the other did not. On each of the fields, three plots of $21.6 \mathrm{~m}^{2}(1.8 \times 12 \mathrm{~m})$ were allocated, with a total of 6 plots. The control plots of each field had no biochar (control-BC0), in other plots was added $1 \mathrm{~kg} / \mathrm{m}^{2}$ of biochar $(\mathrm{BC} 1)$ or $3 \mathrm{~kg} / \mathrm{m}^{2}$ of biochar $(\mathrm{BC} 3)$ to other plots on a one-time basis (Fig.2).

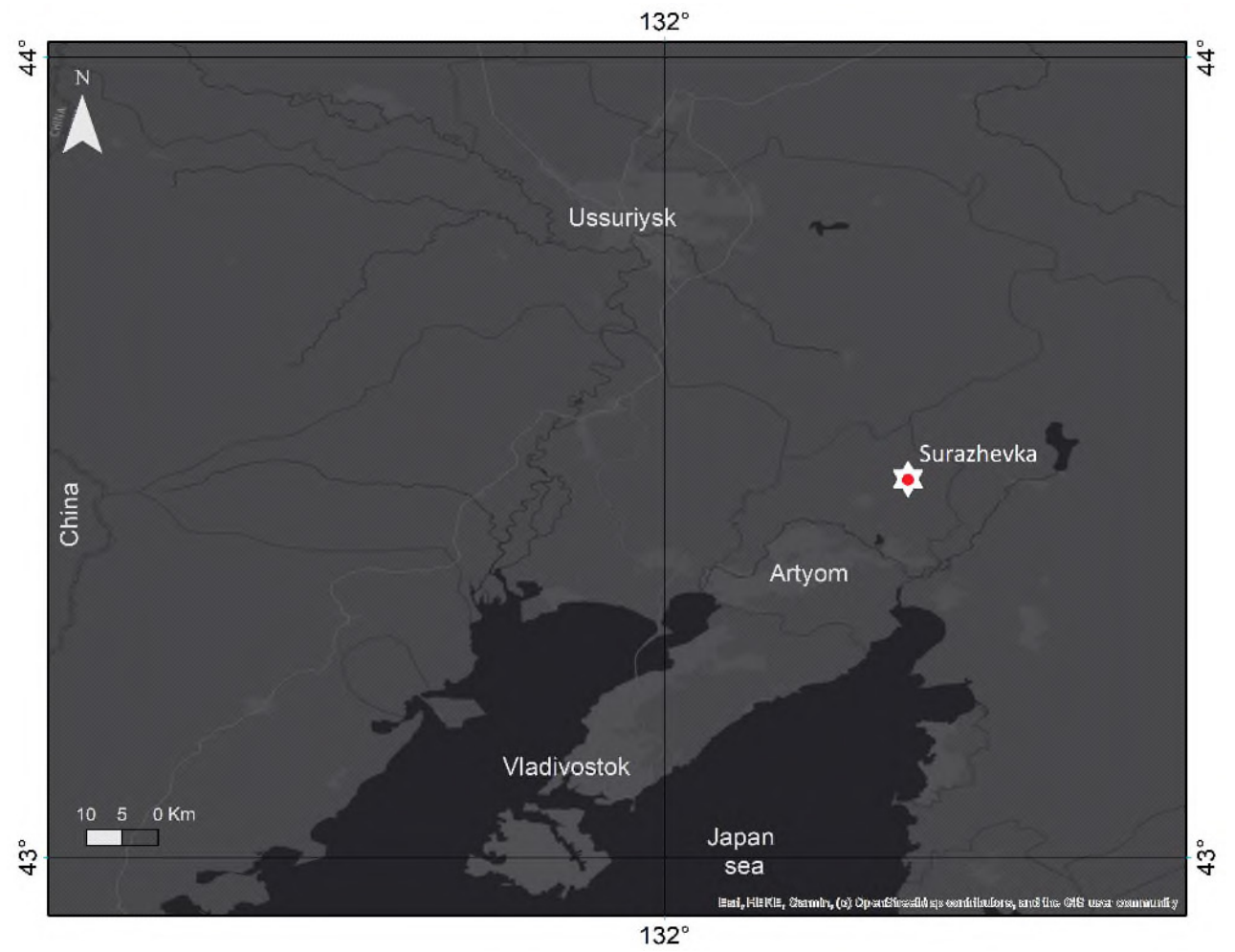

Fig. 1. Study area. 


\begin{tabular}{|c|c|c|c|c|c|}
\hline Fielc & ut dra & istem & \multicolumn{3}{|c|}{ Field with drainage system } \\
\hline $\mathrm{BC} 0$ & $\mathrm{BC} 1$ & $\mathrm{BC} 3$ & $\mathrm{BCD}$ & BCD1 & $\mathrm{BC}$ \\
\hline
\end{tabular}

Fig. 2. Scheme of experiment.

\subsection{Soils}

The soil in the studied areas is represented by Luvic Anthrosols. The arable layer of the control area in the field without a drainage system has an average carbon granulometric composition ( $60 \%$ of physical sand, $40 \%$ of physical clay) close to the neutral reaction of the medium $\left(\mathrm{pH}_{\mathrm{H} 2 \mathrm{O}}=6.8 ; \mathrm{pH}_{\mathrm{KCl}}=5.45\right)$ and a carbon content of $2.62 \%$. The control area in the drainage field has a heavy carbon granulometric composition ( $52 \%$ physical sand, $48 \%$ physical clay) close to the neutral reaction of the medium $\left(\mathrm{pH}_{\mathrm{H} 2 \mathrm{O}}=6.67 ; \mathrm{pH}_{\mathrm{KCl}}=5.43\right)$ and $2.05 \%$ carbon.

\subsection{Biochar}

During the experiment, we used the biochar by "Krasnilov and $\mathrm{K}$ " company, produced from wood residues of Betula alba birch by pyrolysis at a temperature of $360-380^{\circ} \mathrm{C}$. Biochar properties were evaluated before its application to the soil (sample 0BC), after the first growing period (June - October 2018) and after the second growing period (June - October 2019). The field sampling of the biochar was conducted by randomly removing biochar particles from the soil on the test sites where only biochar was introduced. As a result, two samples of biochar after the first growing period were obtained, one from the non-drainage field (1BC) and another from the drainage field (1BCD), and similarly, two biochar samples were selected after the second growing period (2BC and $2 \mathrm{BCD})$. The biochar was introduced once on June 15, 2018.

The biochar properties were evaluated according to the IBI International Standard [9]. Before applying biochar to the soil, the following parameters were determined: $\mathrm{pH}$ according to the method of Rajkovich et al. [10] in triplicate; ash and volatile substances by ASTM D1762-84 in triplicate; size of particles by sieve method (sieve: $0.5 \mathrm{~mm}, 1 \mathrm{~mm}, 2$ $\mathrm{mm}, 4 \mathrm{~mm}, 8 \mathrm{~mm}, 16 \mathrm{~mm}, 25 \mathrm{~mm}, 50 \mathrm{~mm}$ ) in five times repetition; total moisture capacity in three-fold repetition. The content of $\mathrm{C}, \mathrm{N}, \mathrm{H}$ in the biochar was determined by an electronic CHNS analyzer PE2400 Perkin Elmer (USA). The content of $\mathrm{Ca}, \mathrm{Na}, \mathrm{Mg}, \mathrm{K}$, etc., with the exception of oxygen, which was determined by calculation, was determined on a Shimadzu EDX-800 X-ray fluorescent analyzer (Shimadzu, Japan). A number of parameters (hygroscopic humidity, ash content, volatile substances, and total moisture capacity) were determined taking into account the natural fraction of biochar and the fractions sifted through $0.25 \mathrm{~mm}$ and $1 \mathrm{~mm}$ sieves.

\section{Results and discussions}

According to the elemental analysis shown in Table 1, the biochar under study belongs to class I of biochars, since it contains more than $60 \%$ carbon from dry mass, namely $78.13 \%$. It is a toxicologically safe product. In accordance with IBI standard, four of the elements shown in Table 1 ( $\mathrm{Cr}, \mathrm{Ni}, \mathrm{Cu}, \mathrm{Zn}$ ) are classified as hazardous do not exceed maximum permissible concentration (MPC), which makes it possible to call this product 
environmentally friendly. The percentages of $\mathrm{H} / \mathrm{C}$ and $\mathrm{O} / \mathrm{C}$ of 0.0518 and 0.1452 , respectively, were calculated based on the $\mathrm{H}$ and $\mathrm{O}$ contents (Table 1).

Table 1. The elemental composition of the Betula alba biochar produced by Krasnilov and K. Company.

\begin{tabular}{|c|c|c|c|}
\hline Element & Contents, $\%$ & Content, $\mathrm{mg} / \mathrm{kg}$ per dry. Weight & $\begin{array}{l}\text { IBI MPC, mg/kg per dry. } \\
\text { Weight }\end{array}$ \\
\hline $\mathrm{C}$ & 78,130 & 781,30 & - \\
\hline $\mathrm{N}$ & 0,084 & 0,84 & - \\
\hline $\mathrm{O}$ & 11,342 & 113,42 & - \\
\hline $\mathrm{H}$ & 4,044 & 40,44 & - \\
\hline $\mathrm{Ca}$ & 1,770 & 17,70 & - \\
\hline $\mathrm{Na}$ & 0,574 & 5,74 & - \\
\hline $\mathrm{Mg}$ & 0,424 & 4,24 & - \\
\hline $\mathrm{K}$ & 0,415 & 4,15 & - \\
\hline $\mathrm{Si}$ & 0,402 & 4,02 & - \\
\hline $\mathrm{Fe}$ & 0,235 & 2,35 & - \\
\hline $\mathrm{Mn}$ & 0,151 & 1,51 & - \\
\hline $\mathrm{Al}$ & 0,141 & 1,41 & - \\
\hline $\mathrm{Zn}$ & 0,057 & 0,57 & $416-7400$ \\
\hline $\mathrm{S}$ & 0,049 & 0,49 & - \\
\hline $\mathrm{Ti}$ & 0,045 & 0,45 & - \\
\hline $\mathrm{P}$ & 0,044 & 0,44 & - \\
\hline $\mathrm{Cu}$ & 0,014 & 0,14 & $143-6000$ \\
\hline $\mathrm{Sr}$ & 0,008 & 0,08 & - \\
\hline $\mathrm{Cr}$ & 0,005 & 0,05 & $93-1200$ \\
\hline $\mathrm{Ni}$ & 0,004 & 0,04 & $47-420$ \\
\hline
\end{tabular}

According to many authors [10-13], $\mathrm{H} / \mathrm{C}$ and $\mathrm{O} / \mathrm{C}$ ratios provide an indication of the quality of the biochar. The lower the $\mathrm{O}$ and $\mathrm{H}$ content, the stronger the bond between the carbon rings of the biochar, and correspondingly, the lower the ratios, the higher the quality of the product, which has a direct dependence on the rate of its decomposition. Taking this 
account, we assume that the low values of the calculated ratios confirm the high quality of the biochar under study.

The biochar under study has a slightly alkaline reaction of the medium with $\mathrm{pHH} 2 \mathrm{O}=$ 8.09. The ash values (percentage of ash) and volatile compounds (percentage of volatile compounds) vary from $5.4 \%$ to $7.3 \%$ and $29 \%$ to $31.2 \%$, respectively, depending on the size of the fraction. The ash values are increased as the fraction size decreases (Table 2). The smallest ash values are in the natural form, probably due to the presence of more macropores (pores larger than $50[\mathrm{mu}] \mathrm{m}$ ). These indicators, according to research by other authors $[14-17,10]$ are characterized as medium, which is good, because high ash and volatile content can make it difficult for biochar pores to pass and therefore reduce its surface area and sorption capacity [14].

Table 2. Physical-chemical and chemical parameters of biochar from Betula alba by Krasnilov and K Company.

\begin{tabular}{|c|c|c|}
\hline \multirow{2}{*}{ Parameter } & Fraction size & Values \\
\hline \multirow{2}{*}{$\begin{array}{c}\text { Volatiles, } \\
\text { \% from is dry. masses }\end{array}$} & $\begin{array}{c}\text { Not changed } \\
\text { biochar }\end{array}$ & 31,2 \\
\cline { 2 - 3 } & $1 \mathrm{~mm}$ & 29 \\
\cline { 2 - 3 } & $0,25 \mathrm{~mm}$ & 31 \\
\hline \multirow{2}{*}{$\begin{array}{c}\text { Ash-content, } \\
\text { \% from is dry. masses }\end{array}$} & $\begin{array}{c}\text { Not changed } \\
\text { biochar }\end{array}$ & 5,4 \\
\cline { 2 - 3 } & $1 \mathrm{~mm}$ & 6,0 \\
\cline { 2 - 3 } & $0,25 \mathrm{~mm}$ & 7,3 \\
\hline
\end{tabular}

The biochar is able to absorb a mass of water exceeding its own weight. The tests carried out show (Fig. 3) that the largest amount of moisture can be retained by a fraction of $1 \mathrm{~mm}(242 \%)$, and the minimum - by natural biochar (110\%). The $0.25 \mathrm{~mm}$ fraction had a total moisture capacity of $183 \%$. 


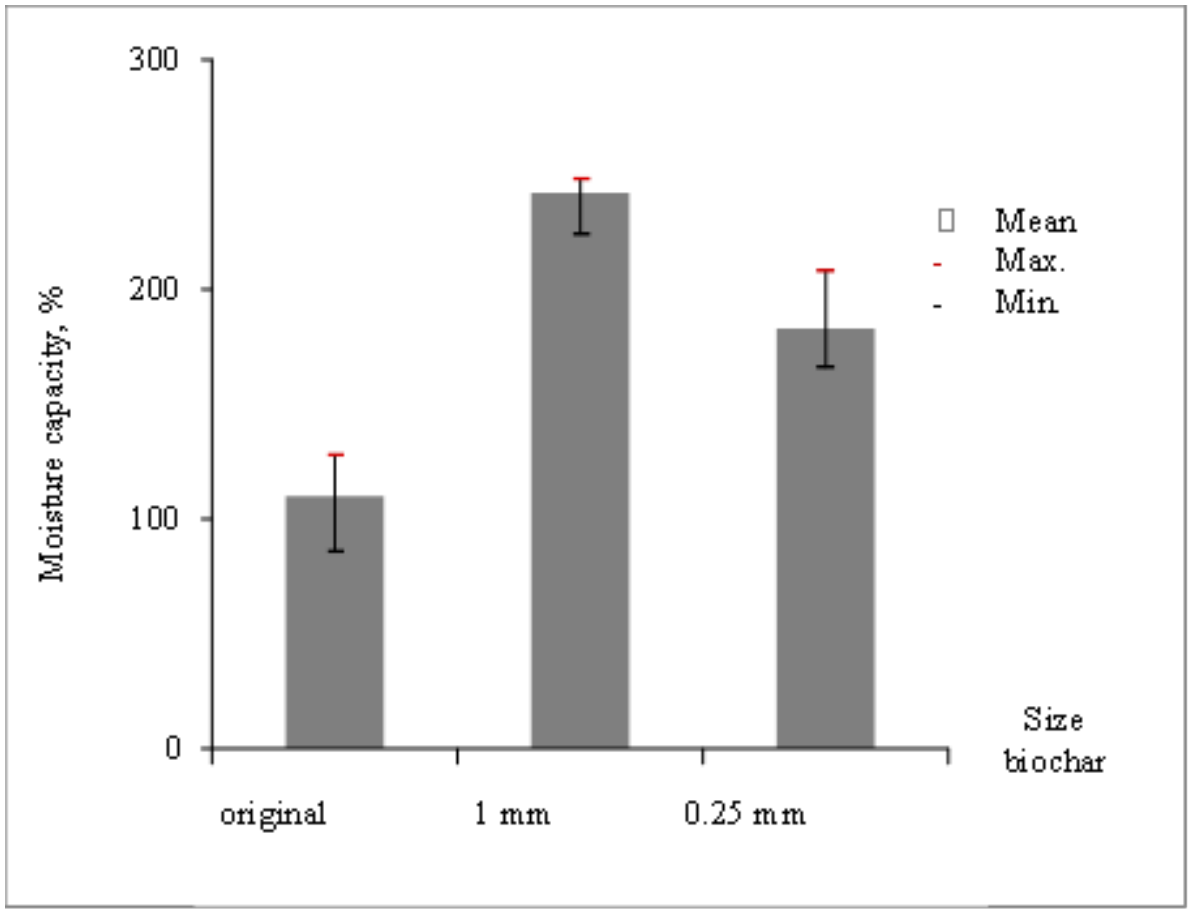

Fig. 3. Full water capacity characteristic of Betula alba biochar.

The results of the granulometric analysis showed that the largest total value of $64.8 \%$ was observed in 4 to $25 \mathrm{~mm}$ fractions, and, as shown in Table 3, the average percentage of the $8-16 \mathrm{~mm}$ fraction was $36.6 \%$, the $16-25 \mathrm{~mm}$ fraction was $13.8 \%$, and the $4-8 \mathrm{~mm}$ fraction was $14.4 \%$.

Table 3. Percentage of Betula alba biochar fractions.

\begin{tabular}{|c|c|c|c|c|c|c|c|c|}
\hline $\begin{array}{l}\text { Size of fractions, } \\
\mathrm{mm}\end{array}$ & $25-50$ & $16-25$ & $8-16$ & $4-8$ & $2-4$ & $1-2$ & $0,5-1$ & $<0,5$ \\
\hline $\begin{array}{c}\text { Contents, } \% \pm \text { St. } \\
\text { dev. }\end{array}$ & $\begin{array}{c}2-8 \\
\pm \\
1,835\end{array}$ & $\begin{array}{c}7-20 \\
\pm \\
4,059\end{array}$ & $\begin{array}{c}29-43 \\
\pm \\
5,711\end{array}$ & $\begin{array}{c}11-18 \\
\pm \\
2,225\end{array}$ & $\begin{array}{c}6-9 \\
\pm \\
1,113\end{array}$ & $\begin{array}{c}4-10 \\
\pm \\
1,835\end{array}$ & $\begin{array}{c}1-4 \\
\pm \\
1,249\end{array}$ & $\begin{array}{c}9-19 \\
\quad \pm \\
3,611\end{array}$ \\
\hline Mean, $\%$ & 5,1 & 13,8 & 36,6 & 14,4 & 7,7 & 7,1 & 2,4 & 12,9 \\
\hline
\end{tabular}

Comparative assessment of the change in biochar properties when applied in agricultural soils.

After applying the biochar in the field growing experiment, changes in its properties after two growing periods were considered. The properties were compared in relation to the properties of biochar before the experiment, and another comparison was made between the properties of biochar used on the field with a drainage system and the one without a drainage system.

The results of the study showed an increasing tendency among all measurable indicators except acidity, especially after the first growing period of using biochar. 
The measured $\mathrm{pH}$ values after the first growing period showed a shift towards the neutral reaction. Thus, in sample $1 \mathrm{BC}$, there was a decrease in $\mathrm{pH}$ level by 1.3 units amounting to 6.729 , and the decrease of 0.7 units in sample 1 BCD amounting to 7.358. After the second vegetative period, in sample $2 \mathrm{BCD} \mathrm{pH}$ made 7.16 which is a slightly lower than in $1 \mathrm{BCD}$. Sample $2 \mathrm{BC}$ showed an increase in $\mathrm{pH}$ towards the alkaline reaction compared to $1 \mathrm{BC}$ reaching 7.248. The decrease in $\mathrm{pH}$ values after the first year of application of the biochar indicates the active interaction of the biochar with soil solution ions and the fixation of soil colloidal particles on the surface of the biochar.

Content of volatiles of biochar after the first vegetative period slightly went down, while a decrease in sample $1 \mathrm{BC}$ was bigger than in 1BCD. Values of ash-content in samples $1 \mathrm{BC}$ and $1 \mathrm{BCD}$ showed a tendency to almost double in comparison with sample $0 \mathrm{BC}$. There is also an increase in ash values with an increase in the surface area of the biochar, that is, with a decrease in the size of the fraction. Thus, in the sample 1BC ash content in the row the original biochar $-1 \mathrm{~mm}-0.25 \mathrm{~mm}$ was $10.6,13.7$ and $17.8 \%$ of the dry weight of the biochar, respectively. In sample $1 \mathrm{BCD}$, the increase in values among original biochar $-1 \mathrm{~mm}-0.25 \mathrm{~mm}$ was similar to the values of sample $1 \mathrm{BC}$, but to a lesser extent.

The obtained values of volatile compounds and ash content allow to speculate on the reasons for their changes. Volatile substances are biogenic volatile elements such as $\mathrm{C}, \mathrm{O}$, $\mathrm{N}, \mathrm{H}$, etc., and substances such as aromatic compounds. Ash elements are biogenic ash elements such as $\mathrm{Si}, \mathrm{Al}, \mathrm{Fe}, \mathrm{Na}, \mathrm{K}, \mathrm{Ca}, \mathrm{P}, \mathrm{Mg}$, etc. So, the first cause of a decrease in volatile substances and an increase in ash elements may be the degradation of biochar in use. This theory is explained by the fact that the biochar degradation expands its specific surface area and consequently increases the number of functional groups actively involved in chemical reactions, thereby increasing the number of ash elements, while increasing the specific surface area makes volatile elements more vulnerable to release. Following this assumption, the decomposition process on the drainage system goes more actively than on the drainage system.

The second reason for the values obtained may be microorganisms stocking the biochar pores. However, microorganisms use mainly volatile biogenic elements and substances in the course of their activity, and little use of ash elements. So, with microorganisms, there would have been a slight increase in ash content and a significant increase in volatile substances, which was not observed in the results obtained.

Another assumption may be the analysis error due to the ingress of soil particles. But this is relevant only for the content of ash elements that interact well with soil colloids.

The assumption about increasing the specific surface area of biochar due to its decomposition is more consistent with the results obtained, and the water-retaining capacity results support this idea. Table 4 shows that after the vegetative period, there was nearly a double increase in water-retaining capacity of biochar amounting to $197 \%$ for sample $1 \mathrm{BC}$ and $217 \%$ for $1 \mathrm{BCD}$. After the second vegetative period, in sample $2 \mathrm{BC}$ the value of waterretaining capacity increased by $29 \%$ in comparison with $1 \mathrm{BC}$ and made up $226 \%$, and in $2 \mathrm{BCD}$ it slightly decreased $(213 \%)$, that is, it practically remained unaltered. It has been mentioned that the reason for the increase in these values may be an increase in the specific surface area of the biochar. 
Table 4. Chemical and Physical Values of the Biochar in Samples Before Application in a Field Growing Experiment, After the First and Second Growing Periods.

\begin{tabular}{|c|c|c|c|c|c|c|}
\hline \multicolumn{2}{|c|}{ Parameter } & $0 \mathrm{BC}$ & $1 \mathrm{BC}$ & $1 \mathrm{BCD}$ & $2 \mathrm{BC}$ & 2BCD \\
\hline \multicolumn{2}{|c|}{$\mathrm{pH}$} & 8,09 & 6,729 & 7,358 & 7,160 & 7,248 \\
\hline \multirow{3}{*}{$\begin{array}{l}\text { Volatiles, } \\
\% \text { from is dry. } \\
\text { masses }\end{array}$} & Original & 31,2 & 27,6 & 30,9 & - & - \\
\hline & $1 \mathrm{MM}$ & 29 & 28,6 & 28,1 & - & - \\
\hline & $0,25 \mathrm{MM}$ & 31 & 28,4 & 27,7 & - & - \\
\hline \multirow{3}{*}{$\begin{array}{l}\text { Ash-content, } \\
\% \text { from is dry. } \\
\text { masses }\end{array}$} & Original & 5,4 & 10,4 & 10,6 & - & - \\
\hline & $1 \mathrm{MM}$ & 6,0 & 13,7 & 10,3 & - & - \\
\hline & $0,25 \mathrm{MM}$ & 7,3 & 17,8 & 12,8 & - & - \\
\hline \multirow{3}{*}{$\begin{array}{l}\text { Water holding } \\
\text { capacity, } \%\end{array}$} & Original & 110 & 197 & 217 & 226 & 213 \\
\hline & $1 \mathrm{MM}$ & 242 & - & - & - & - \\
\hline & $0,25 \mathrm{MM}$ & 183 & - & - & - & - \\
\hline
\end{tabular}

\section{Conclusion}

The evaluation of the properties of biochar before its application in the field growing experiment showed that the biochar under study is environmentally friendly, of high quality, it has a strong high porous structure and good sorption properties with a high $\mathrm{C}$ percentage $(78,13 \%)$, a $\mathrm{pH}$ value of 8.09 , an ash content within the range of $5.4 \%$ to $7.3 \%$ and it contains volatile compounds in the range of $29 \%$ to $31.2 \%$.

The use of biochar has shown that its chemical and physical characteristics change significantly when contacted with soil and the environment, which is noticeable after the first growing period of use. So, $\mathrm{pH}$ values in sample 1BC and 1BCD decreased by 1.3 and 0.7 units and were 6.7 and 7.4, respectively. Volatile compounds value showed a small reduction, for several percent, while a decrease in sample $1 \mathrm{BC}$ was more significant than in 1BCD. After the first growing period, the ash content of the biochar doubled on average and amounted to $10.6 \%$ of the dry mass of the original biochar fraction in sample $1 \mathrm{BC}$, $13.7 \%$ of the dry mass in $1 \mathrm{~mm}$ fraction, and $17.8 \%$ of the dry mass in $0.25 \mathrm{~mm}$ fraction. In sample $1 \mathrm{BCD}$, the ash content was $10.6 \%, 10.3 \%$, and $12.8 \%$ of dry mass, respectively. Water retention capacity values have increased dramatically. Compared to the values in sample $0 \mathrm{BC}$ for the fraction of original biochar (110\%), samples $1 \mathrm{BC}$ and 1BCD showed an increase in indicators by 87 and $107 \%$ which made up 197 and $217 \%$, respectively. A slight increase in water retention capacity was recorded in the samples of the second growing period as compared to the first one.

The findings suggest that the main reason for the changes in the properties of the biochar after its application during the growing field experiment is the increase in the specific surface area due to the decomposition process. Yet, the change of biochar properties caused by its decomposition goes faster on a field without a drainage system than on a field with a drainage system, and the speed of these changes is generally more evident after the first growing period of application.

The research was carried out with the financial support of the Russian Foundation for basic research under project № 19-29-05166. 


\section{References}

1. S. Shackley, S. Sohi, R. Ibarrola, J. Hammond, Encyclopedia of Sustainability Science and Tecnology, 845 - 893 (2012) DOI: 10.1007/978-1-4419-0851-3_386

2. J. Lehman, Y. Kuzyakov, G. Pan, Y. Ok, Plant Soil, 395, 1-5 (2015) DOI: 10.1007/s11104-015-2658-3

3. W. Busscher, J.M. Novak, E. Dean, et al., Soil Science, 175, 10 - 14 (2010) DOI: 10.1097/SS.0b013e3181cb7f46

4. S.R. Brockhoff, N.E. Christians, R.J. Killorn, R. Horton, D.D. Davis, Agronomy journal, 102, 1627 - 1631 (2010) DOI: 10.2134/agronj2010.0188

5. H. Asai, B.K. Samson, H.M. Stephan, et al., Field Crops Research, 111, 81 - 84 (2009) DOI: 10.1016/j.fcr.2008.10.008 13

6. Y. Ding, Y. Liu, S. Liu, et al., Agron. Sustain. Dev., 36(2), 36 (2016) DOI: 10.1007/s13593-016-0372-Z

7. X. Ren, H. Sun, F. Wang, F. Cao, Chemosphere, 144, 2257 - 2263 (2016) DOI: 10.1016/j.chemosphere.2015.10.132

8. A.R. Zimmerman, Environ. Sci. Technol., 44, 1295 - 1301 (2010) DOI: $10.1021 /$ es 903140 c

9. Product Definition and Specification Standards: Standardized Product Definition and Product Testing Guidelines for Biochar That Is Used in Soil (IBI Biochar Standards) Version 2.1. (IBI, 2015)

10. S. Rajkovich, A. Enders, K. Hanley, et al., Biology and Fertiloty of Soil, 48, $271-284$ (2012) DOI: 10.1007/s00374-011-0624-7

11. K.A. Spokas, Carbon Management, 1(2), 289 - 303 (2010) DOI: 10.4155/cmt.10.32

12. K.H. Kim, J.-Y. Kim, T.-S. Cho, J.W. Choi, Bioredource Technology, 118, 158 - 162 (2012) DOI: 10.1016/j.biortech.2012.04.094

13. M.I. Al-Webel, A.Al-Omran, A.H. El-Naggar, et al., Bioresource technology, 131, 374-379 (2013) DOI: 10.1016/j.biortech.2012.12.165

14. A. Shah, M. J. Darr, D. Dalluge, D. Medic, K. Webster, R. C. Brown, Bioresource Technology, 125, 348 - 352 (2012) DOI: 10.1016/j.biortech.2012.09.061

15. E.H. Novotny, C.M.B.F. Maia, M.T.M. Carvalho, B.E. Madari, Revista Brasileira de Ciencia do Solo, 39, 321 - 344 (2015) DOI: 10.1590/01000683rbcs20140818

16. H. Wang, X. Wang, Y. Gui, Z. Xue, Y. Ba, Bioresource Technology, 263, 444 - 449 (2018) DOI: 10.1016/j.biortech.2018.05.040

17. S.M. Taha, M.E. Amer, A.E. Elmarsafy, M.Y. Elkady, Environmental Chrmical Engineering, 2, 2013 - 2025 (2014) DOI: 10.1016/j.jece.2014.09.001 